\title{
Influence of roughness on initial in vitro response of cells to Al203/Ce-TZP nanocomposite
}

\section{Suárez, S. Pérez-López, C. Prado, A. Fernández, J. S. Moya, R. Torrecillas \&} L. A. Díaz

To cite this article: M. Suárez, S. Pérez-López, C. Prado, A. Fernández, J. S. Moya, R. Torrecillas \& L. A. Díaz (2021) Influence of roughness on initial in vitro response of cells to Al2O3/Ce-TZP nanocomposite, Journal of Asian Ceramic Societies, 9:1, 131-141, DOI: 10.1080/21870764.2020.1856311

To link to this article: https://doi.org/10.1080/21870764.2020.1856311

(2) 2021 The Author(s). Published by Informa UK Limited, trading as Taylor \& Francis Group on behalf of The Korean Ceramic Society and The Ceramic Society of Japan.

Published online: 23 Dec 2020.

Submit your article to this journal $\sqsubset$

Џll Article views: 1919

Q View related articles ๘

View Crossmark data ¿ 


\title{
Influence of roughness on initial in vitro response of cells to Al2O3/Ce-TZP nanocomposite
}

\author{
M. Suárez $\mathbb{D}^{\mathrm{a}, \mathrm{b}}$, S. Pérez-López ${ }^{\mathrm{c,d}}$, C. Prado $\mathbb{D}^{\mathrm{a}}{ }^{\mathrm{a}}$, A. Fernández $\mathbb{D}^{\mathrm{a}, \mathrm{b}}$, J. S. Moya ${ }^{\mathrm{a}, \mathrm{b}}, \mathrm{R}$. Torrecillas $\mathbb{D}^{\mathrm{a}, \mathrm{b}}$ \\ and L. A. Díaz $(\mathbb{D})^{a, b}$
}

${ }^{a}$ Centro de Investigación en Nanomateriales y Nanotecnología (CINN) Consejo Superior de Investigaciones Científicas (CSIC) - Universidad

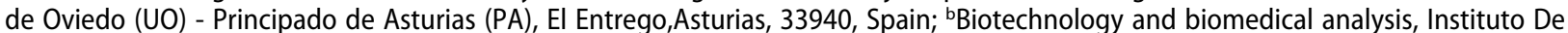
Investigación Sanitaria Del Principado De Asturias, Oviedo, Spain; 'Unidad de Terapia Celular y Medicina Regenerativa, Servicio de Hematología y Hemoterapia, Hospital Universitario Central de Asturias, Oviedo, Asturias, 33011, Spain; ${ }^{d}$ Metabolism Research Area, Instituto De Investigación Sanitaria Del Principado De Asturias, Oviedo, Spain

\begin{abstract}
$\mathrm{Al}_{2} \mathrm{O}_{3} / \mathrm{Ce}$-tetragonal zirconia polycrystal (TZP) nanocomposite was synthesized by a colloidal processing route and sintered in air atmosphere. Sandblasting treatment was made to alumina toughened zirconia (ATZ) nanocomposite in order to evaluate the influence of surface roughness on the osteogenic differentiation performing in vitro growing a human osteoblast-like cell line, SaOs-2, and human adipose-derived mesenchymal stem cells (hADMSC) osteogenic differentiated. Smooth roughness values around $R a=0.5 \mu \mathrm{m}$ were obtained when the abrasive material was below $90 \mu \mathrm{m}$ increasing the expression of BGLAP and IBSP genes and $R a=1.5 \mu \mathrm{m}$ was found with particles of sizes between 90 and $250 \mu \mathrm{m}$ upregulating SPARC gene. The non-cytotoxicity and haemocompatibility of ATZ nanocomposite were proved. Alumina-ceria-stabilized zirconia nanocomposite presented in this work exhibits a high potential for application in the fabrication of dental implants due to their biological behavior and very promising mechanical properties.
\end{abstract}

\section{ARTICLE HISTORY}

Received 28 July 2020

Accepted 20 November 2020

\section{KEYWORDS}

Nanocomposite; roughness; biocompatibility;

$\mathrm{Al}_{2} \mathrm{O}_{3} / \mathrm{Ce}-\mathrm{TZP}$

\section{Introduction}

For more than 40 years, commercially pure titanium and titanium alloys were widely used as dental implant materials due to their excellent biocompatibility, early osseointegration and high corrosion resistance [1]. Nevertheless, titanium may induce allergic reactions or sensitivities [2] and it possesses a dark color that could be exposed during peri-implant mucosa recession and ruin the entire esthetic result [3]. As a viable alternative to resolve these problems, some new ceramic materials were developed. Bioceramic materials offer excellent opportunities to combine the absence of metal ions, good bone ingrowth characteristics and improved esthetics due to the possibility of dying the product with pigments. In this context, alumina $\left(\mathrm{Al}_{2} \mathrm{O}_{3}\right)$ was the first bioceramic used as an implant material [4], due to its low friction, wettability, wear resistance and biocompatibility. However, it showed insufficient physical properties. In the $80 \mathrm{~s}$, zirconia $\left(\mathrm{ZrO}_{2}\right)$ emerged as a ceramic material valid for implants because of its improved fracture toughness and mechanical strength with respect to alumina. Tetragonal zirconia polycrystals, specially 3 mol\% yttria-stabilized zirconia (3Y-TZP), serves as a metal substitute in substrates and possesses good physical characteristics; its bending strength doubles and its fracture toughness almost triples that of alumina [5]. Nevertheless, the big disadvantage of pure 3Y-TZP is its low temperature degradation (LTD) [6]. Actually, combining the positive properties of $\mathrm{Al}_{2} \mathrm{O}_{3}$ (wear resistance, hydrothermal stability and hardness) with those of $\mathrm{ZrO}_{2}$ (strength and fracture toughness) it is possible to obtain alumina toughened zirconia (ATZ) and zirconia toughened alumina (ZTA) nanocomposites with a higher potential for application as dental implants [7]. Among them, composite materials with Ce-TZP and alumina have shown very promising mechanical properties to be used in the fabrication of implants [8]. Besides the mechanical properties of the bulk material, the characteristics of an implant's surface, such as composition, topography and roughness play an important role in cell-material integration and biocompatibility [9]. The interaction between cells and a biomaterial's surface is fundamentally relevant and essential in terms of the response of cells at the interface, affecting the growth and quality of newly formed bone tissue $[10,11]$. For this reason, cell culture models are routinely used to study the response of osteoblastic cells in contact with different substrates for

CONTACT M. Suárez m.suarez@cinn.es Centro De Investigación En Nanomateriales Y Nanotecnología (CINN) Consejo Superior De Investigaciones Científicas (CSIC), Universidad De Oviedo (UO), Principado De Asturias (PA), El Entrego, Asturias 33940, Spain

This article has been corrected with minor changes. These changes do not impact the academic content of the article.

(4) Supplemental data for this article can be accessed here. 
implantation in bone tissue. Moreover, human adiposederived mesenchymal stem cells (hADMSC) are considered to contain a group of pluripotent mesenchymal stem cells and manifest multilineage differentiation capacity, including osteogenesis, chondrogenesis and adipogenesis [12]. These last cells could differentiate into odontogenic lineage, expressing bone marker proteins, and might be used as suitable seeding cells for tooth regeneration [13]. Few data are available concerning the response of mesenchymal stem cells to ATZ. The purpose of the present study was to perform in vitro osteogenic differentiation assays growing a human osteoblast-like cell line, SaOs-2, and hADMSCs on different ATZ supports in order to determine the influence of the composition and surface roughness on the behavior of the cells in relation with these new implants. In this context, different tests were performed to study cytotoxicity, viability, hemolysis and differences in terms of osteogenic and apoptotic gene expression between the samples.

\section{Materials and methods}

The $\mathrm{Al}_{2} \mathrm{O}_{3} / \mathrm{Ce}$-TZP nanocomposite was made using the following materials: Ce-TZP (10 mol\% $\left.\mathrm{CeO}_{2}\right)$ from Daichi (Japan) with an average particle size of $35 \mathrm{~nm}\left(\mathrm{~d}_{50}\right)$ and a specific surface area of $15 \mathrm{~m}^{2} \cdot \mathrm{gr}^{-1}$, $\mathrm{a}-\mathrm{Al}_{2} \mathrm{O}_{3}$ powder (TM DAR, Taimei Chemical Co., Japan) with a specific surface area of $14.6 \mathrm{~m}^{2} \cdot \mathrm{gr}^{-1}$ and an average particle size $\left(d_{50}\right)$ of $150 \mathrm{~nm}$. In addition, the following chemical precursors were also used: i) aluminum chloride (Sigma-Aldrich, Spain), ii) zirconium IV-propoxide (70\% solution in 1-propanol) (SigmaAldrich, Spain), iii) 2-Propanol (99.9\% Panreac, Spain) and iv) absolute ethanol (99.97\% Panreac, Spain). A colloidal processing route described in Rivera et al. [14] and L. A. Díaz et al. [15] was followed in order to obtain the nanocomposite. In this route CeTZP was coated by an alumina amorphous layer, using aluminum chloride as precursor and subsequently thermally treated in order to activate the formation of $\gamma$-alumina transition phase. After this, the alumina powders were also coating with zirconia nanoparticles using a zirconium propoxide as chemical precursor. Finally, both chemically modified raw materials (zirconia and alumina) were mixed using a ratio of $80 / 20$ in volume, respectively, in a polypropylene container with zirconia balls for $72 \mathrm{~h}$ in order to ensure a good homogeneity of the mixture. After this, the material was dried at $120^{\circ} \mathrm{C}$, grounded and sieved through $<63$ microns mesh.

\subsection{Disk specimen preparation}

The powders were cold isostatically pressed at $300 \mathrm{MPa}$ into cylindrical rods of $50 \mathrm{~mm}$ in length and $9 \mathrm{~mm}$ in diameter. After surface machining and firing at $1475^{\circ} \mathrm{C}$ for $1 \mathrm{~h}$, disk-shaped specimens of $7 \mathrm{~mm}$ diameter and $1.3 \mathrm{~mm}$ thickness were prepared by cutting and polishing (applying microcrystalline diamonds of 9,3 and 1 microns). In total, 36 disks were used for sandblasting tests and six disks more were used as target specimens.

\subsection{Sandblasting process}

Disks were sandblasted with white corundum and SiC powders (see Table 1). Laser diffraction (Beckman Coulter LS 13 320, USA) was used for the granulometric characterization of the selected fractions. The air pressure was applied perpendicular to the surface of the disk at 0.4 bars and at a distance of $10 \mathrm{~mm}$ using sandblaster equipment (Sandblaster I, Astursinter, Spain).

\subsection{Surface roughness and morphology}

The morphology of the samples and the raw materials used in the process of sandblasting was characterized by field emission scanning electron microscopy (FESEM) (FEl: Quanta FEG 650, USA). The surface roughness of the specimens was analyzed using a surface roughness tester (MicroTest: MT4002, Spain). Six measurements on each specimen according to ISO 4287-1997 [16] were performed. The assessed profile $(R a)$ as an arithmetical mean deviation was calculated. The ratio of monoclinic and tetragonal $\left(X_{m}\right)$ and the amount of transformation (monoclinic volume content, $\mathrm{v}_{\mathrm{m}}$ ) induced by sandblasting were determined by X-ray diffraction (XRD) (Bruker D8 Advance, Germany) using the equations (1) and (2) described in Toraya et al. [17].

$$
X_{m}=\frac{I_{m}(\overline{1} 11)+I_{m}(111)}{I_{m}(\overline{1} 11)+I_{m}(111)+I_{t}(111)}
$$

Where

$I_{m}(\overline{1} 11)$ is the peak height of monoclinic phase at around $2 \theta=28.2^{\circ}$

$I_{m}(111)$ is the peak height of monoclinic phase at around $2 \theta=31.3^{\circ}$

$I_{t}(111)$ is the peak height of tetragonal phase at around $2 \theta=30.2^{\circ}$

$$
v_{m}=\frac{P X_{m}}{1+(P-1) X_{m}}
$$

where $P$ was a constant with value of 1.311 .

This behavior was studied with a Tuttnauer Autoclave (2540EL, Tuttnauer, NY, USA) following ISO 13,356:2015 [18]. In this way, samples were placed in a suitable

Table 1. Sample references and materials used for surface treatment.

\begin{tabular}{ll}
\hline Samples & \multicolumn{1}{c}{ Sandblasting material } \\
\hline Sample NA & Non sandblasted sample (control) \\
Sample A & White Corundum $<90 \mu \mathrm{m}, 60 \mathrm{~s}$ \\
Sample B & $90 \mu \mathrm{m}<\mathrm{SiC}<250 \mu \mathrm{m}, 15 \mathrm{~s}$ \\
Sample C & $\mathrm{SiC}<90 \mu \mathrm{m}, 15 \mathrm{~s}$ \\
\hline
\end{tabular}


autoclave and exposed to steam at $134^{\circ} \mathrm{C}$ under a pressure of $0.2 \mathrm{MPa}$ for a period of $5 \mathrm{~h}$. After this period, cool the autoclave and remove and dry the test specimens.

\subsection{In vitro studies methodology}

Different tests were carried out in order to assess the biocompatibility, non-cytotoxicity and haemocompatibility of the $\mathrm{Al}_{2} \mathrm{O}_{3} / \mathrm{Ce}$-TZP nanocomposite:

(1) Human adipose-derived mesenchymal stem cells (hADMSCs) isolation and culture: hADMSCs were isolated from abdominal subcutaneous adipose tissue. Adipose tissue was submitted to mechanical digestion and then digested with collagenase I (Sigma-Aldrich, USA) DMEM solution (Lonza, Belgium) and the cell suspension was filtered and centrifuged. The obtained cell fraction was cultured in expansion medium to $80 \%$ confluence, at $5 \% \mathrm{CO}_{2}$ and $37^{\circ} \mathrm{C}$. Finally, cells were harvested using Trypsin-EDTA 1X (Biowest, France).

(2) Cytotoxicity tests using the neutral red uptake (NRU) assay and the MTS assay. The potential cytotoxic effect of materials on mammalian cells was determined following ISO 10,993-part 5 [19] for biomaterials and medical device testing. Samples were sterilized before use. SaOs-2 cells (human osteosarcoma cells, kindly provided by the SCT of the University of Oviedo, Spain) or human MSCs from adipose tissue were seeded onto 48-well plates at a density of approximately $4 \cdot 10^{4}$ cells $/ \mathrm{ml} / \mathrm{cm}^{2}$ and cultured until achieving confluence. Then, samples were placed in contact with the cell monolayer. In the NRU test, the uptake of NR into the lysosomes/endosomes and vacuoles of living cells are used as a quantitative indication of viability. Cells were washed after $24 \mathrm{~h}$ and incubated with neutral red solution (Scharlab, Spain) for $3 \mathrm{~h}$. After that, cells were washed again and NR was desorbed by adding a mixture of ethanol and acetic acid. The amount of NR extracted from the cells was measured at $540 \mathrm{~nm}$ and the percentage of viable cells was calculated (equation 3).

$\%$ of viable cells $=100$

$$
\times \operatorname{Abs}_{540}(\text { extract }) / \mathrm{Abs}_{540}(\text { blank })
$$

In the MTS assay, culture medium was removed after $24 \mathrm{~h}$ and fresh medium with MTS solution (CellTiter $96^{\circledR}$ AQueous One Solution Cell Proliferation Assay, Promega, USA) (5:1) was added to each well. After 3-4 additional hours in the presence of MTS, absorbance was determined at
$490 \mathrm{~nm}$ and the percentage viability was calculated (equation 4).

$\%$ of viable cells $=100$

$$
\times \mathrm{Abs}_{490}(\text { extract }) / \mathrm{Abs}_{490}(\text { blank })
$$

(3) Hemolysis index (ASTM F 756-08 [20]): $\mathrm{Hb}$ released into plasma when blood was exposed to the materials was measured: After a period of incubation, samples were removed and tubes were centrifuged. Each supernatant $(100 \mu \mathrm{L})$ were mixed with Drabkin's reagent $(100 \mu \mathrm{L})$ and cyanmethemoglobin was produced and detected by spectrophotometry at $540 \mathrm{~nm}$. Total blood hemoglobin (TBH) was also measured. The hemolytic index was calculated (equation 5).

Hemolytic Index $=\mathrm{Hb}$ released $\left(\frac{\mathrm{mg}}{\mathrm{mL}}\right) / \mathrm{TBH}\left(\frac{\mathrm{mg}}{\mathrm{mL}}\right)$

(4) Osteogenic differentiation of SaOs-2 (human osteoblast-like cell line) and hADMSCs: Cells were seeded at a density of $50 \times 10^{3}$ cells on each of the four kinds of samples until confluence and cultured in differentiation medium supplemented with dexamethasone, ascorbic acid and $\beta$-glycerol phosphate (all reagents from Sigma-Aldrich, USA). Every $72 \mathrm{~h}$, differentiation medium was changed, and in 3 weeks, the whole differentiation process was completed. In order to confirm the adequate osteogenic differentiation, alkaline phosphatase and alizarin red staining were performed.

(5) Alkaline phosphatase staining: Differentiated osteogenic cells were fixed with formaldehyde (Merck, Germany), stained with a BCIP/NBT solution (SIGMA FAST ${ }^{\text {тм }}$ BCIP/NBT, Sigma-Aldrich, USA) and observed by microscopy.

(6) Alizarin red staining: Differentiated osteogenic cells were fixed with paraformaldehyde, stained with alizarin red solution (Merck, Germany) and observed by microscopy.

(7) RNA extraction and cDNA synthesis: Total RNA was isolated using Tri reagent ${ }^{\circledR}$ solution (Ambion, USA). After evaluating the quality of the RNA through absorbance measurements, each RNA sample was reverse transcribed to obtain cDNA samples.

(8) Real-Time quantitative polymerase chain reaction: Quantitative PCR was performed using a CFX96 Real-Time System (Bio-Rad, Hercules, CA, USA). Fluorescence data during the primer extension step were acquired. The melting-curve analysis, to confirm product specificity, was performed immediately after amplification, following $1 \mathrm{~min}$ of denaturation at $95^{\circ} \mathrm{C}, 1 \mathrm{~min}$ of annealing at $65^{\circ} \mathrm{C}$ 
and 60 cycles of $0.5^{\circ} \mathrm{C}$ increments (30 s each) beginning at $65^{\circ} \mathrm{C}$ while monitoring fluorescence. $\beta$-ACTIN (ACTB) was used as the endogenous control. This gene encodes one of six different actin proteins that are involved in cell motility, structure, integrity and intercellular signaling. Alkaline Phosphatase, Biomineralization Associated (ALPL) that may play a role in bone mineralization, Bone Gamma-Carboxyglutamate Protein or Osteocalcine (BGLAP) that contains Gla which functions in binding to calcium and hydroxyapatite, Collagen Type I (COL1) found in most connective tissues, Integrin Binding Sialoprotein (IBSP) that encoded the major structural protein of bone matrix and Secreted Protein Acidic and Cysteine Rich or Osteonectin (SPARC) required for the collagen in bone are used as bone differentiation genes. CASPASE 3 is used as an indicator of apoptotic damage.

(9) Statistical analysis: Data using the Proc MIXED procedure of the SAS/STAT v8.2 software package (SAS Institute, Inc., Cary, NC, USA) were statistically analyzed. $C t$ values (number of cycles needed to generate a fluorescent signal above a predefined threshold) and $\Delta C$ t values (difference between the $C t$ of the target gene and that of the housekeeping gene) for each gene and repetition were used as dependent variables. To quantify gene expression levels a relative standard method was used. The model fitted included the type of sample as the fixed effect and the sample as a random effect to account for the non-independency of the repetitions. For each sample level, least-square means and their corresponding standard errors were computed.
For descriptive purposes, a Student's $t$ test $t$ on raw $C t$ means computed for samples using Proc GLM of SAS/STAT was also carried out, assuming that the sample type effect included two independent groups of normally distributed observations.

\section{Results}

\subsection{FESEM}

The representative microstructure of the sintered ATZ nanocomposite is shown in Figure 1 where two different phases can be observed. The lightest one corresponds to the Ce-TZP matrix with a particle size of $400-500 \mathrm{~nm}$ and the darkest phase corresponds to alumina with an average size of $250 \mathrm{~nm}$. As it can be observed alumina grains are homogeneously distributed in the Ce-TZP matrix and no pores are observed. Grains with straight edges appeared in both phases indicating that the sintering process has been completed.

\subsection{Surface roughness}

Sandblasting is a commonly used surface treatment and involves impacting with hard particles at high velocities on a surface in order to erode it and leave a roughened surface with expected higher wettability. The FESEM micrographs of the modified ATZ surfaces by sandblasting with white corundum and silicon carbide for 60 $\mathrm{s}$ and $15 \mathrm{~s}$ are shown in Figure 2(a-c). Sandblasting with white corundum and SiC particles $<90$ microns (Figure 2(a and c), respectively), revealed a regular and

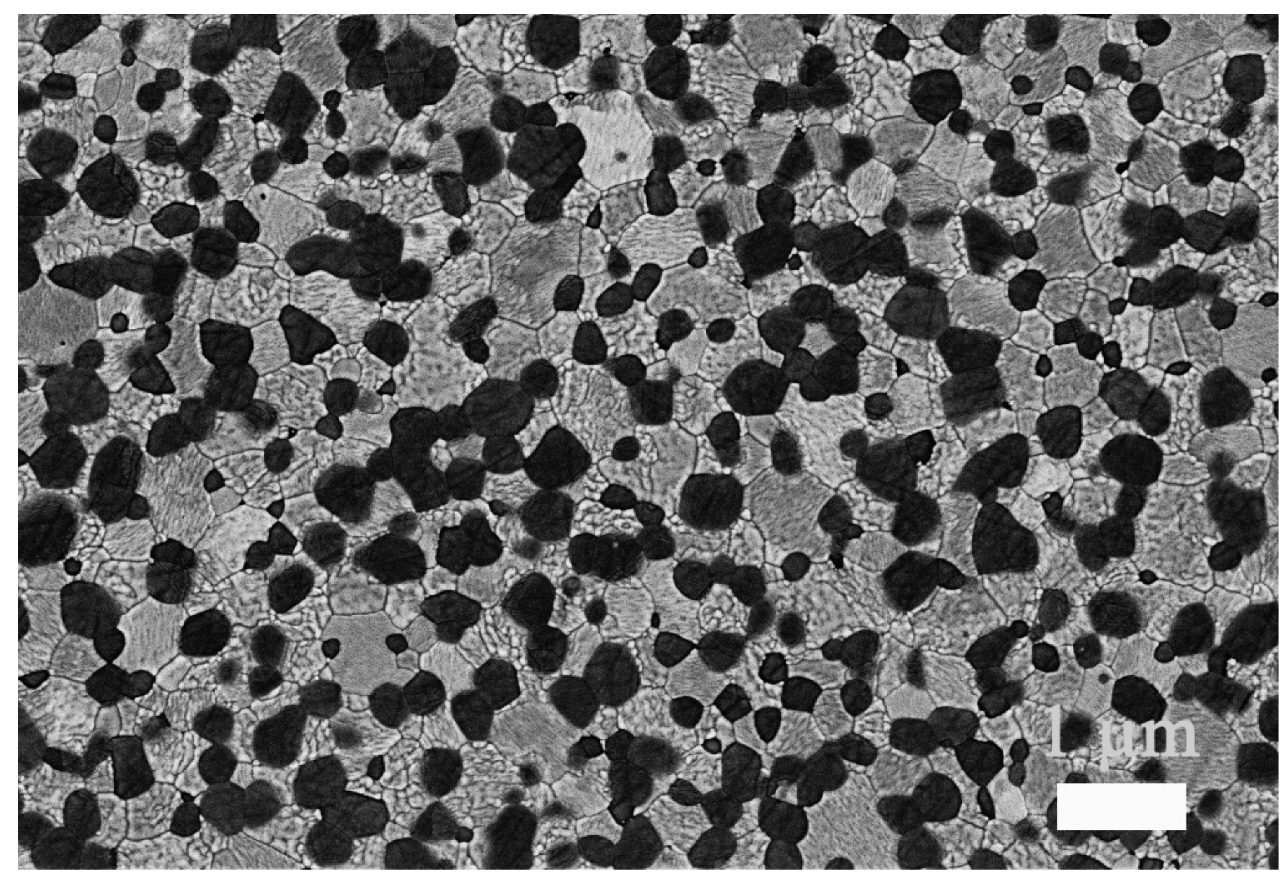

Figure 1. FESEM microstructure of polished surface of the ATZ nanocomposite. 

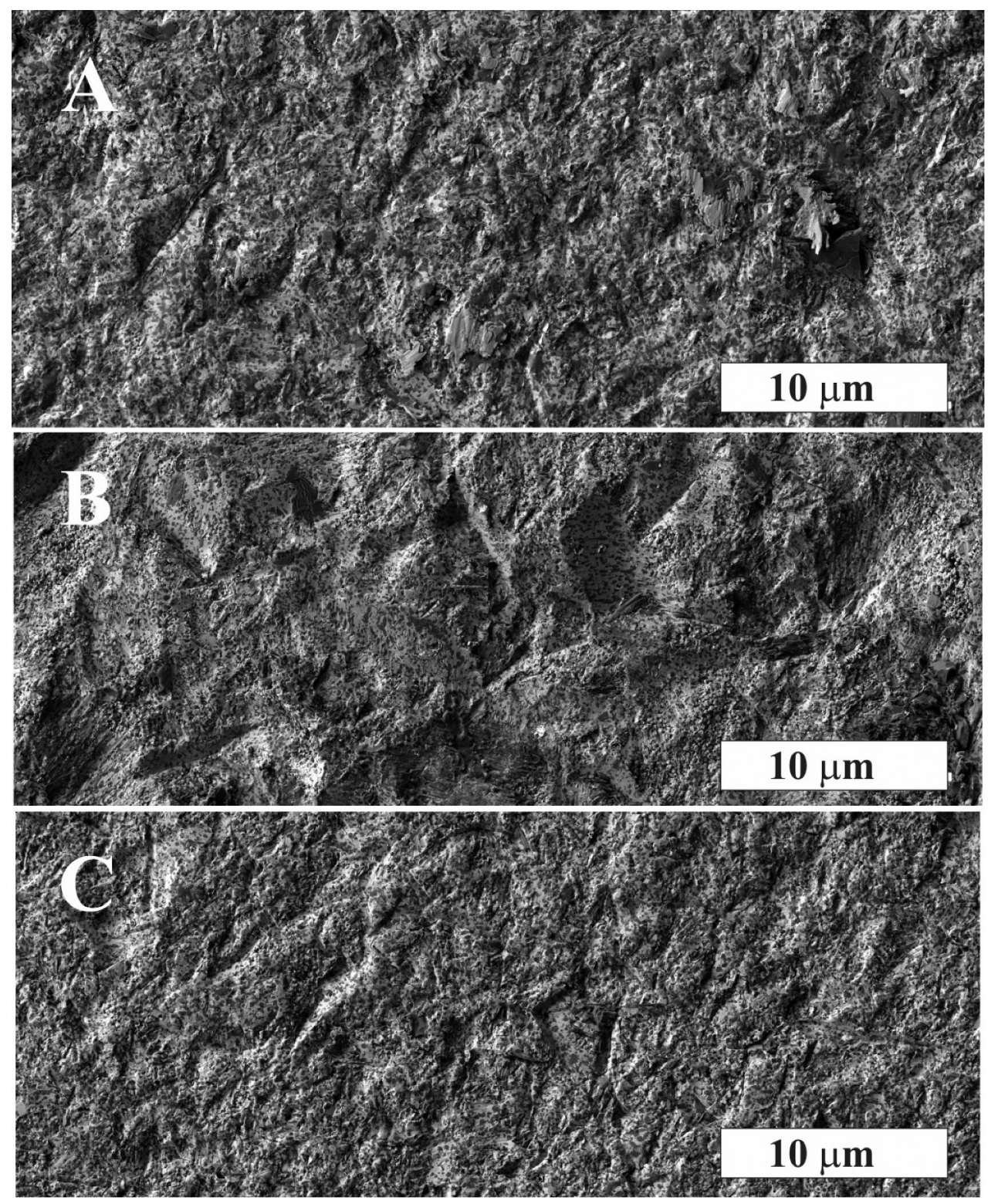

Figure 2. FESEM images from the topographical appearance of sandblasted surfaces with white corundum and silicon carbide raw materials. (a) White corundum < $90 \mathrm{~mm}$ time: $60 \mathrm{~s}$; (b) SiC < $250 \mathrm{~mm}$ and $>90 \mathrm{~mm}$ time: $15 \mathrm{~s}$; and (c) SiC < $90 \mathrm{~mm}$ time: $15 \mathrm{~s}$.

Table 2. Roughness values of the ATZ nanocomposite surfaces after sandblasting with corundum and SiC for 60 and $15 \mathrm{~s}$ (mean \pm SD in $\mu \mathrm{m}$ ). N.A (No Sandblasting).

\begin{tabular}{lccc}
\hline Raw materials & Ra $<0.5 \mu \mathrm{m}$ & $0.5 \mu \mathrm{m}<\mathrm{Ra}<1.0 \mu \mathrm{m}$ & $1.0 \mu \mathrm{m}<\mathrm{Ra}<2.0 \mu \mathrm{m}$ \\
\hline W.C. $<90 \mu \mathrm{m}, 60 \mathrm{~s}$ & Smooth & Minimally rough & Moderately rough \\
$\mathrm{SiC} 250-90 \mu \mathrm{m}, 15 \mathrm{~s}$ & $0.465 \pm 0.06$ & $0.580 \pm 0.08$ & $1.358 \pm 0.11$ \\
$\mathrm{SiC}<90 \mu \mathrm{m}, 15 \mathrm{~s}$ & $0.031 \pm 0.10$ & & Rough \\
N. A & & & \\
\hline
\end{tabular}

slightly waved structure. However, the surface of the sandblasted ATZ with SiC particles between 90 and $250 \mu \mathrm{m}$ (Figure 2(b)) showed a more irregular structure with visibly larger voids and grooves, increasing the surface roughness according to the results shown in Table 2 for ATZ samples. The mean roughness index, $\mathrm{Ra}$ (arithmetical mean deviation of the profile), in case of samples sandblasted with $\mathrm{SiC}$ between 90 and 250 microns was significantly higher than the other sandblasted samples. According to the Altbrektsson and Wennerberg classification [19], the samples sandblasted with white corundum present a "smooth" surface roughness $(R a<0,5 \mu \mathrm{m})$, while the samples sandblasted with SiC show "minimally rough" and "moderately rough" surface roughness. Similar results have been found by Sato et al. [20] where sandblasting by SiC particles resulted in surface roughness values larger than those by alumina particles. 

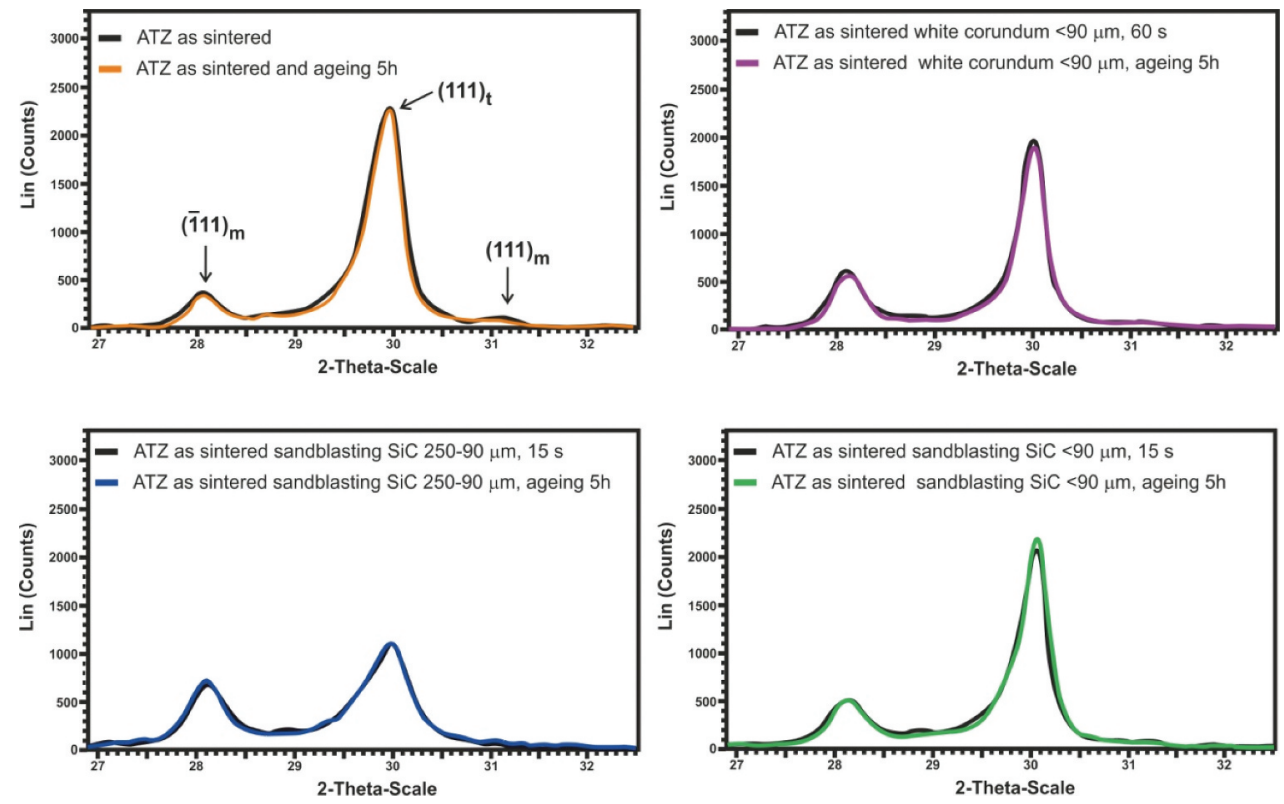

Figure 3. X-ray diffraction patterns for ATZ samples: as sintering; as sintering and sandblasting process; as sintering, sandblasting and aging process (see Table 3 ).

\subsection{XRD diffraction}

X-ray diffraction (XRD) patterns of characterized samples are shown in Figure 3. The materials do not present spontaneous phase transformation on their surface after sintering and any aging process. However, sandblasting processes lead to the transformation, under tension, of a part of the tetragonal zirconia to monoclinic zirconia since an increase of the intensity of monoclinic peak (111) $\mathrm{m}$ with respect to the tetragonal peak (111) t can be observed. The volumetric fraction $\left(v_{m}\right)$ of the monoclinic phase is calculated according to equations (1) and (2) on (1) as-sintered surfaces, (2) as-sintered surfaces after sandblasting process, (3) as-sintered surfaces after sandblasting and its aging process and the results are shown in Table 3. The particle size and the kind of material used for the sandblasted process have an effect on the transformation phase of ATZ composite [21]. In this sense, the

Table 3. Volumetric fractions of monoclinic phase zirconia present on different sandblasted surfaces.

\begin{tabular}{lc}
\hline Treatment & $\begin{array}{c}\text { Monoclinic phase } \\
\text { content }\left(\mathrm{V}_{\text {mtotal }}\right)\end{array}$ \\
\hline ATZ as-sintered & $3,80 \% \pm 3 \%$ \\
ATZ as-sintered and aging during $5 \mathrm{~h}$ & $2,10 \% \pm 3 \%$ \\
ATZ as-sintered sandblasting surface by white & $24,73 \% \pm 3 \%$ \\
$\quad$ corundum $<90 \mu \mathrm{m}, 60 \mathrm{~s}$ & \\
ATZ as-sintered sandblasting surface by white & $27,00 \% \pm 3 \%$ \\
$\quad$ corundum $<90 \mu \mathrm{m}, 60 \mathrm{~s}$ aging during $5 \mathrm{~h}$ & \\
ATZ as-sintered sandblasting surface by SiC & $48,70 \% \pm 3 \%$ \\
$\quad 250-90 \mu \mathrm{m}, 15 \mathrm{~s}$ & \\
ATZ as-sintered sandblasting surface by SiC & $50,00 \% \pm 3 \%$ \\
$\quad 250-90 \mu \mathrm{m}, 15 \mathrm{~s}$ aging during $5 \mathrm{~h}$ & \\
ATZ as-sintered sandblasting surface by SiC & $31,70 \% \pm 3 \%$ \\
$\quad<90 \mu \mathrm{m}, 15 \mathrm{~s}$ & \\
ATZ as-sintered sandblasting surface by SiC & $36,00 \% \pm 3 \%$ \\
$\quad<90 \mu \mathrm{m}, 15 \mathrm{~s}$ aging during $5 \mathrm{~h}$ & \\
\hline
\end{tabular}

effect of sandblasting on the monoclinic content was larger in case of $\mathrm{SiC}$ particles than alumina particles since it depends on the difference in the hardness of the material: e.g. the Vickers hardness of $\mathrm{Al}_{2} \mathrm{O}_{3}$ and $\mathrm{SiC}$ is 1800 and 2200 , respectively. Furthermore, increasing the particle size increases the erosion of material and the transformation surface layer. This transformation process is reversible and, in every case, a posterior thermal treatment at $1200^{\circ} \mathrm{C}$ for $15 \mathrm{~min}$ succeeds in transforming the totality of the monoclinic zirconia back to its initial tetragonal state [22].

\subsection{In vitro biological assays}

ISO $10,993-5$ [23] states that a material is considered non-cytotoxic when cell viability is above $70 \%$. The potential cytotoxicity on SaOs-2 and hADMSCs was assessed by the MTS assay and the NRU method using tissue culture polystyrene (TCPS) as the blank. According to the results shown in Figure 4( $a$ and $b)$ all of the studied samples allowed for higher than $90 \%$ cell viability; therefore, none of the surface modification treatments can be considered cytotoxic.

Hemolysis is the alteration, dissolution or destruction of red blood cells that results in hemoglobin liberation into the surrounding medium. According to Stanley's classification criteria, a material is considered non-hemolytic for hemolytic indexes $<2$ while it is considered slightly hemolytic and hemolytic for hemolytic index values of $2-5$ and $>5$, respectively. Different factors such as surface roughness, surface energy and surface tension and surface wettability can have an influence on the blood compatibility and it is shown that surface modification has a great 

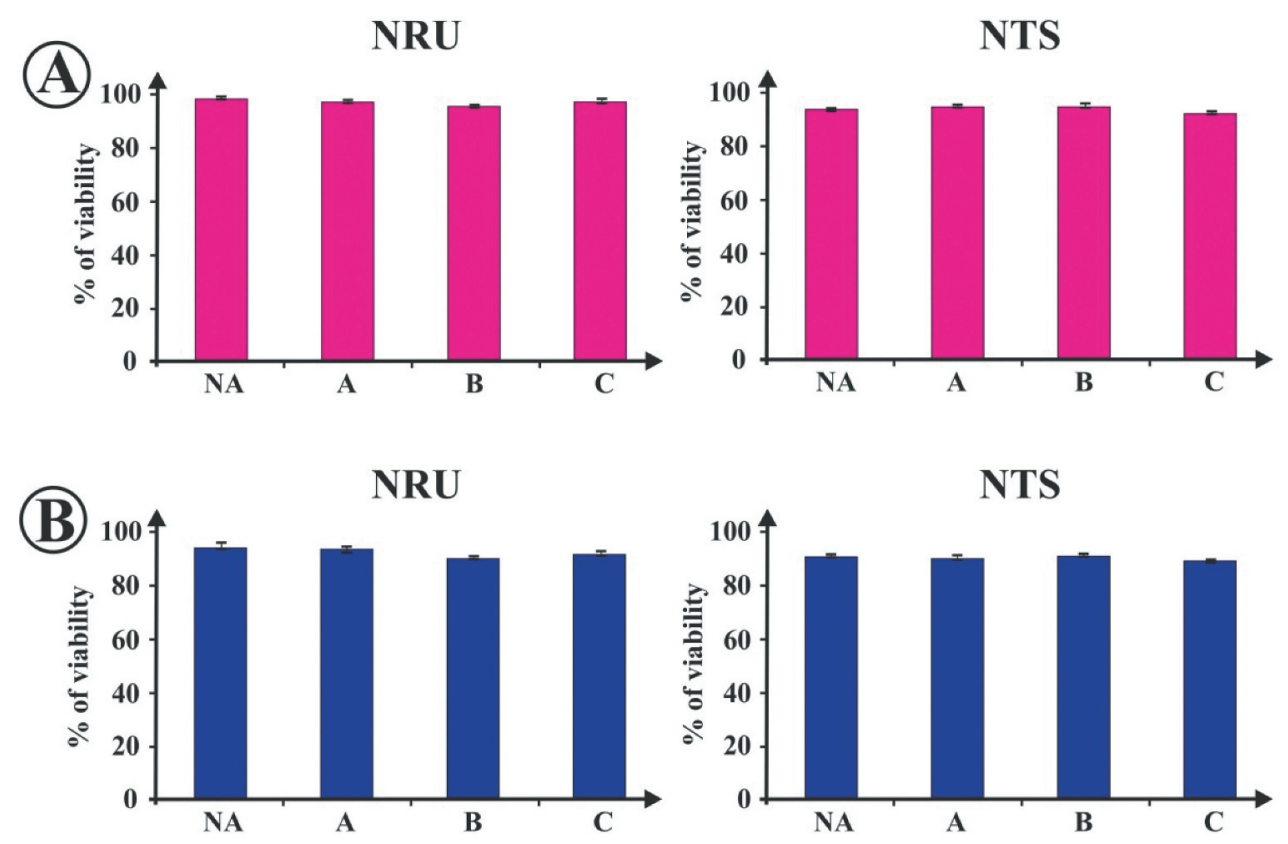

Figure 4. Biological assessment: NRU and MTS assay. No reduction in cell viability was observed for either the SaOs-2 (a) or the hADMSC (b) cells for any of the surface modifications tested, since the percentage viability was always superior to $70 \%$. Bars represent the means $(\mathrm{SD})$ of triplicate measurements.

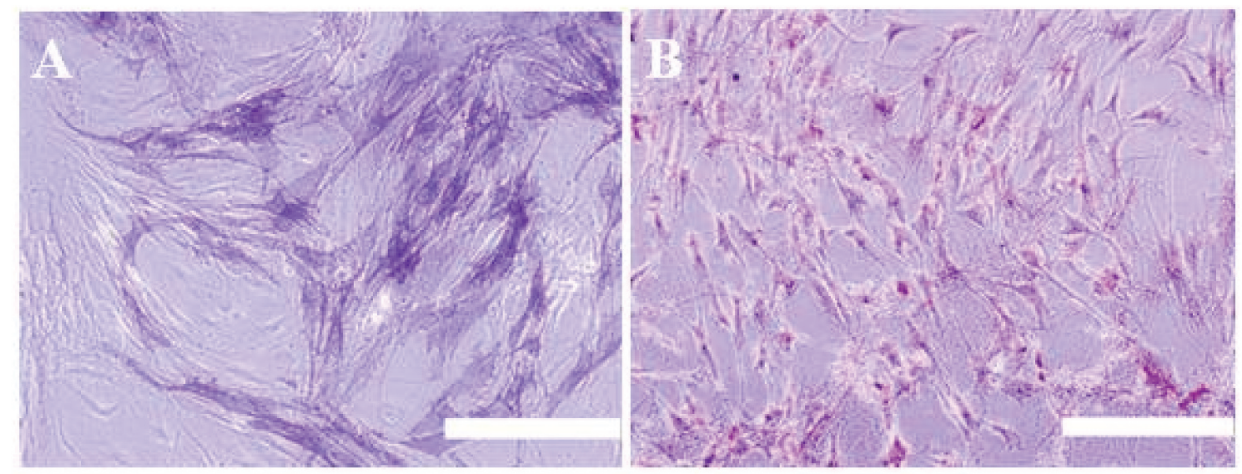

Figure 5. Alkaline phosphatase staining (a) and alizarin red staining (b) on substrate after hADMSCs incubation. White bar represents 500 microns.

potential for improving the hemocompatibility of biomedical materials and devices [24]. In this case, the studied ATZ nanocomposite showed a hemolytic index close to $0(0.1-0.2)$ for all the surface modifications tested, which was $<1 \%$ indicating nonhemolytic material.

ALP levels increase when active bone formation (osseous differentiation) occurs, as it is a by-product of this process. According to the results shown in Figure 5(a and b) a correct osteoblast differentiation of hADMSCs has been taken placed since all of the differentiated cells used for gene expression studies were stained and, consequently, osteoblast differentiation confirmed.

Product identity was confirmed by electrophoresis on ethidium bromide-stained $2 \%$ agarose gels in $1 \mathrm{X}$ TBE buffer, which resulted in a single product of the desired length. In addition, an iCycleriQ melting curve analysis was performed, which rendered single product specific melting temperatures. No primer-dimers were generated during the 40 real-time PCR cycles conducted. All polymerase chain reaction efficiencies were above $90 \%$ and linearity was high, with correlation coefficients $\left(R^{2}\right)$ above 0.989 .

To quantify gene expression, the relative standard method (relative fold changes) was used and expression levels were determined for the ceramics and the control group (NA sample) by normalizing results with respect to $\beta$-ACTIN. For hADMSCs, a discreet increase was noticed in the relative expression of four of the studied genes for samples $A, B$ and $C$ when compared with the control sample. In Figure $6(\mathrm{a})$, these increases are plotted. In the problem group, the genes BGLAP, CASPASE 3, IBSP and SPARC were up-regulated 2.27fold for sample A, 1.57-fold for sample C, 3.10-fold for 

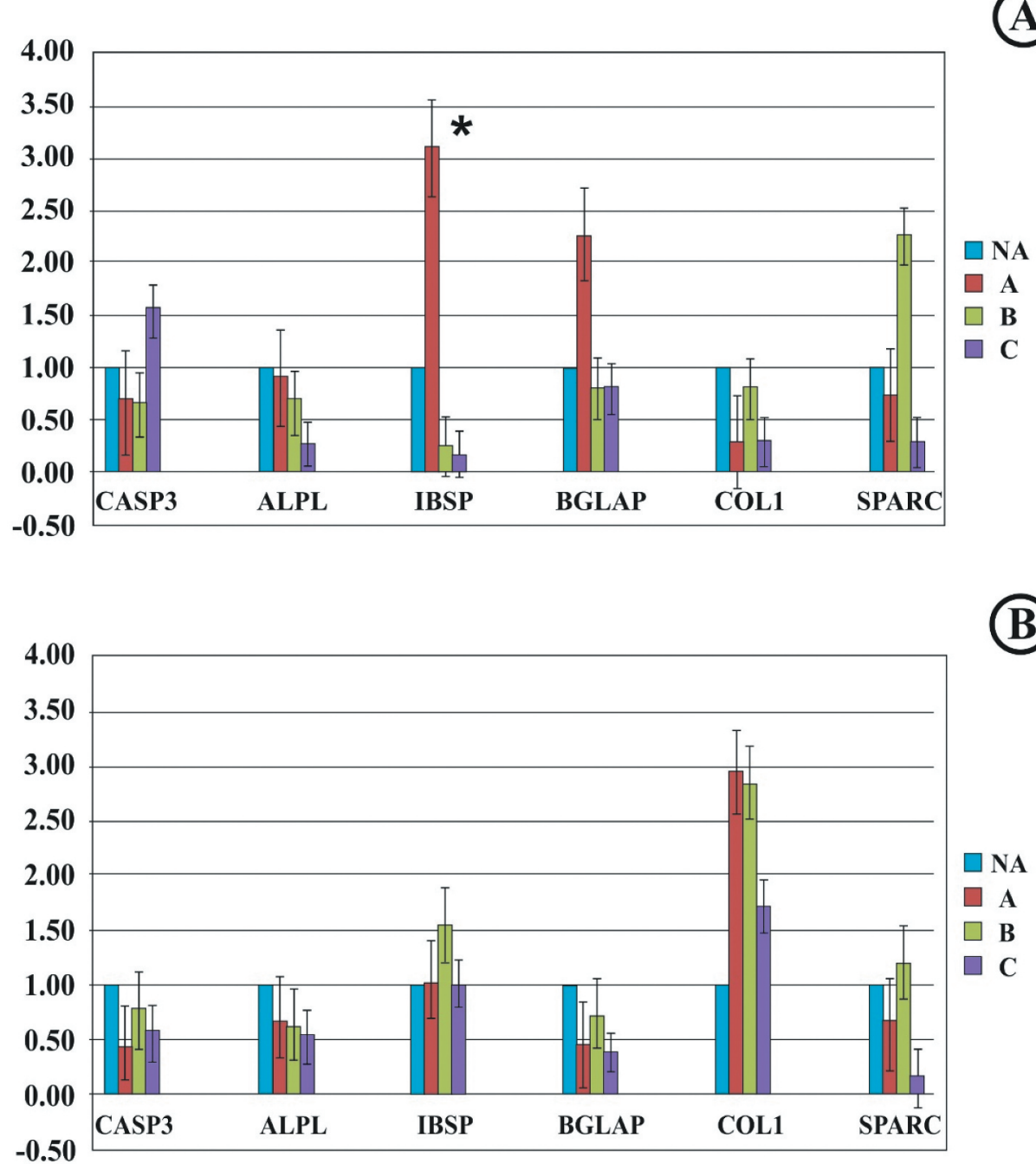

Figure 6. Relative quantification of the studied genes to day 21. mRNA levels for apoptotic and bone differentiation genes recorded in hADMSCs (upper part) and SaOs-2 cells relative to endogenous control gene $\beta$-ACTIN levels. Values are expressed as mean \pm SEM. ${ }^{*}$ indicates a significant difference with respect to the controls at $p$ less than 0.05 .

sample A, and 2.27-fold for sample B, respectively, with respect to the basal levels recorded for the endogenous control ( $\beta$-ACTIN). However, these increases were only significant $(p<0.05)$ in the case of IBSP for sample A.

In the case of the SaOs cells, an even more discreet increase was observed in the relative expression of two of the studied genes for samples $A, B$ and $C$ when compared with the NA sample (control). These results are also shown in Figure $6(\mathrm{~b})$. The IBSP gene is 1.55 -fold up-regulated for sample $B$. The COL1A1 gene is upregulated 2.95-fold for sample $A, 2.85$-fold for sample $B$ and 1.74-fold for sample $C$ with respect to the basal levels recorded for the endogenous control. In this case, differences between control and problem groups were not significant.

\section{Discussion}

The alumina toughened zirconia (ATZ) biomaterial studied in this work is a nanocomposite that combines the properties of $\mathrm{Al}_{2} \mathrm{O}_{3}$ and $\mathrm{Ce}-\mathrm{ZrO}_{2}$. Moreover, Ce-TZP does not suffer low temperature degradation. The good combination of mechanical properties of this nanocomposite has already been proven [14] and now it is necessary to confirm its good interaction with cells.

The ideal material to make implants should not be purely tolerated by the host but should interact with biological systems in a way that induces the appropriate host response for a specific application [25] controlled by the proteins that coat the surface of the biomaterial. The nature and activity of the proteins adsorbed on the surface depend on its physical and chemical properties. In fact, the biomaterial's surface properties such as topography and hydrophilicity will be determinant in terms of biocompatibility and other biological phenomena. Topography also can modify the shape and activity of mesenchymal stem cells leading to a higher differentiation rate of these cells into osteogenic lineage with the upregulation of osteoblastic genes [26]. 
Zhang $Y$ et al. [27] showed how surface roughness affects osteoclastic differentiation as well as the stimulatory effects of osteoclasts on osteogenic differentiation of osteoprogenitor cells. Concerning osteoblast differentiation microscale surface roughness has been shown to enhance osseointegration of titanium implants through increased osteoblast differentiation while osteoblast proliferation remains greater on smooth titanium [28]. According to the literature, surfaces with $R a \leq 1 \mu \mathrm{m}$ are considered smooth and those with $R a>1 \mu \mathrm{m}$ are described as rough. In general, the surface roughness range that favors osseous differentiation has been reported to be 1.0-1.5 $\mu \mathrm{m}$ [29].

Sandblasting is known to form surface roughness and irregularities on surface materials and, in the particular case of zirconia, induces a transformation from tetragonal to monoclinic phase due to the stress generated during the process [30]. Human cells were preferably attached to hydrophilic surfaces than hydrophobic ones. For this reason, the modification of the surface allows increasing the surface area and wettability of the ceramic surface, increasing protein adsorption, promoting the attachment, proliferation and differentiation of human cells. According to the literature [31], increasing surface areas would be more favorable for cell attachment due to mechanical interlocking at the initial cell attachment stage.

In the present study, SaOs- 2 cells and hADMSC cells were used to investigate the influence of roughness on regulation of cell viability, hemolysis and osseous differentiation. According to the results obtained in the cytotoxicity and hemolysis experiments, the data obtained in our study revealed that there are no significant differences in the responses of osteogenic cells and hADMSCs toward the different surface modification treatments in terms of biocompatibility. In fact, none of the surface modification treatments induced significant cell death in osteoblasts, hADMSC or erythrocytes. Similar results regarding cell viability and hemolysis have been published over the years [32]. Given the bioinertness of ceramic materials, such as those studied in this work, treatments to modify the surface and provide a suitable environment are necessary in order to trigger a favorable biological response in terms of osseous differentiation.

Concerning gene expression, different osteogenic genes were studied in order to determine differences between samples. For hADMSCs, the increase was only lightly observed in the case of four genes BGLAP, CASPASE3, IBSP and SPARC. BGLAP was upregulated 2.27-fold for sample $A$, CASPASE3 was upregulated 1.57-fold for sample $C$, IBSP was upregulated 3.10-fold for sample $A$ and, finally, SPARC was up-regulated 2.27-fold for sample $B$ with respect to the basal levels. However, the increase was only significant $(p<0.05)$ in the case of IBSP in sample A. These findings, in terms of gene expression as well as histological results, showed that the roughness and the nature of the material are adequate to allow cells to achieve osteogenic differentiation, despite the fact that the surface roughness of the studied samples is clearly below the $R$ a values reported to favor osseous differentiation $(1.0-1.5 \mu \mathrm{m})$. It is important to note that osteoblastic differentiation of MSCs into functional differentiated osteoblasts requires a series of steps involving the expression of different proteins at each stage. Alkaline phosphatase is regarded as a marker of early osteoblastic differentiation. In fact, it is the main signal that compromises cells to differentiate toward osteoblastic lineage; in a similar way, COL1 gene is over-expressed in the pre-osteoblastic phase coinciding with the beginning of the bone tissue-differentiating cascade, whereas secretion of Osteocalcin and IBSP as well as matrix mineralization is associated with the final differentiation phase. The observation of an increasing expression of IBSP with significant differences between groups for white corundum (sample A) showed that the differences in terms of osteogenic differentiation seem not to appear until the last phases, meaning that the gene expression pattern is similar for all samples during the entire process. Significantly, the main increase observed in IBSP is in agreement with the results obtained by Wang and cols [33] that pointed out the importance of the integrin-linked kinase/ $\beta$-catenin pathway in mediating signals from topographic cues to direct the osteogenic differentiation of cells. For SaOs-2 cells, the three samples (A, B and C) showed upregulation related to sample NA (control) for two of the studied genes, IBSP and COL1. These results are correlated with the different levels of roughness showed for the different samples, since NA shows the smoothest one. Moreover, these results also are according to the concept that the roughness affects the attachment and spreading of cells, showing that probably the number of osteoblastic cells is higher in the rough supports. However, this upregulation was not signification any case. The expected pattern for SaOs- 2 cells is clearly different from that of hADMSC because it is a human osteoblast-like cell line itself and it is supposed to express osteogenic genes such as COL1 at the beginning of the bone tissue differentiating cascade or IBSP that are over expressed at middle-to-late osteogenic differentiation. These observations are in agreement with Czekanska et al. [34], who described high levels of expression of osteocalcin, bone sialoprotein, decorin and procollagen-I. For both types of cells (hADMSCs and SaOs-2), the apoptotic gene studied, Caspase-3, did not show important differences between samples, meaning that neither material nor roughness had a clear influence on cell death. This circumstance is in agreement 
with the absence of deleterious effects on cell viability.

\section{Conclusions}

The non-cytotoxicity and haemocompatibility of a nanocomposite ceramic material formed by alumina and ceria stabilized zirconia has been proved. The surface roughness of this nanocomposite can be adjusted depending on the particle size of the materials used for sandblasting. Smooth roughness values of around $0.5 \mu \mathrm{m}$ are obtained when the abrasive material (white corundum or silicon carbide) is below $90 \mu \mathrm{m}$, while the use of silicon carbide particles of sizes between 90 and $250 \mu \mathrm{m}$ leads to surface roughness values of around $1.5 \mu \mathrm{m}$. Moreover, the roughness and the nature of the material used have been proved adequate for cell osteogenic differentiation. An increase in the expression of BGLAP and IBSP genes was observed on samples sandblasted with white corundum below $90 \mu \mathrm{m}$, whereas SPARC gene was upregulated on samples sandblasted with $\mathrm{SiC}$ between 90 and $250 \mu \mathrm{m}$. Then, the studied nanocomposite is a very promising material for dental applications thanks to its good mechanical properties in comparison with conventional ceramics, the possibility of adjusting its surface roughness and the different in vitro results obtained.

\section{Acknowledgments}

The Spanish Ministry of Science, Innovation and Universities and the Spanish Higher Council for Scientific Research (CSIC) have supported this research under the Projects MAT2012-38645 and INPERIO, H2020-SMEInst -2018-2020-2 Ref CSIC-20185222, respectively. Catuxa Prado acknowledges financial support from the JAE-DOC program (CSIC).

\section{Disclosure statement}

This manuscript has a registered preprint (DOI: 10.21203/rs.3. rs-44,864/v1) with the following link https://www.researchs quare.com/article/rs-44864/v1. No potential conflict of interest was reported by the authors.

\section{Funding}

This work was supported by The Spanish Ministry of Science, Innovation and Universities and the Spanish Higher Council for Scientific Research (CSIC) under the Projects MAT201238645 and INPERIO, H2020-SMEInst-2018-2020-2 Ref CSIC20185222, respectively. Catuxa Prado acknowledges financial support from the JAE-DOC program (CSIC).

\section{ORCID}

M. Suárez (D) http://orcid.org/0000-0001-9764-0861

C. Prado (ID) http://orcid.org/0000-0002-6630-4395
A. Fernández (D) http://orcid.org/0000-0002-8742-4572

R. Torrecillas (D) http://orcid.org/0000-0003-3856-0217

L. A. Díaz (D) http://orcid.org/0000-0003-4895-464X

\section{References}

[1] Sidambe TA. Biocompatibility of advanced manufactured titanium implants-a review. Materials. 2014;7 (12):8168-8188.

[2] Sicilia A, Cuesta S, Coma G, et al. Titanium allergy in dental implant patients: a clinical study on 1500 consecutive patients. Clin Oral Implants Res. 2008;19 (8):823-835.

[3] den Hartog L, Raghoebar GM, Slater JJH, et al. Singletooth implants with different neck designs: a randomized clinical trial evaluating the aesthetic outcome. Clin Implant Dent Relat Res. 2013;15 (3):311-321.

[4] Schulte W. The Tubinger immediate implant. Quintessenz. 1976;27:17-23.

[5] Garvie RC, Hannink RH, Pascoe RT. Ceramic steel? Nature. 1975;258(5537):703-704.

[6] Chevalier J, Gremillard L, Deville S. Low-temperature degradation of zirconia and implications for biomedical implants. Annu Rev Mater Res. 2007;37(1):1-32.

[7] Chevalier J, Gremillard L. Ceramics for medical applications: a picture for the next 20 years. J Eur Ceram Soc. 2009;29(7):1245-1255.

[8] Benzaid R, Chevalier J, Saâdaoui M, et al. Fracture toughness, strength and slow crack growth in a ceria stabilized zirconia-alumina nanocomposite for medical applications. Biomaterials. 2008;29 (27):3636-3641.

[9] Wennerberg A, Albrektsson T, Andersson B. An animal study of c.p. titanium screws with different surface topographies. J Mater Sci. 1995;6:302-309.

[10] Lamers E, Frank Walboomers X, Domanski M, et al. The influence of nanoscale grooved substrates on osteoblast behavior and extracellular matrix deposition. Biomaterials. 2010;31(12):3307-3316.

[11] Pae A, Lee $\mathrm{H}$, Kim H-S, et al. Attachment and growth behaviour of human gingival fibroblasts on titanium and zirconia ceramic surfaces. Biomed Mater. 2009;4 (2):025005.

[12] Liu TM, Martina M, Hutmacher DW, et al. Identification of common pathways mediating differentiation of bone marrow- and adipose tissue-derived human mesenchymal stem cells into three mesenchymal lineages. Stem Cells. 2007;25(3):750-760.

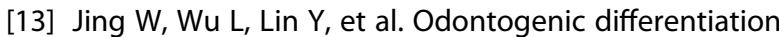
of adipose-derived stem cells for tooth regeneration necessity, possibility, and strategy. Med Hypotheses. 2008;70(3):540-542.

[14] Rivera S, Diaz L, Fernández A, et al. Reinforcement mechanisms in alumina toughened zirconia nanocomposites with different stabilizing agents. In Mathur $\mathrm{S}$, Hernandez-Ramirez F, Kirihara S, Widjaja S, editors. Proceedings of the 37th International Conference on Advanced Ceramics and Composites. Daytona Beach: Florida; 2013 Jan 27- Feb 1. p. 15-22

[15] Díaz LA, Torrecillas R. Material compuesto nanoestructurado de circona estabilizada con ceria y alúmina dopada con circona. procedimiento de obtenión y usos. Spain patent ES 2351759 A1. 2011 Feb 10.

[16] ISO 4287. 1997: geometric product specification (GPS). Surface texture profile method: terms, definition and 
surface texture parameters. Geneva: International Organisation Standard; 1997.

[17] Toraya H, Yoshimura M, Somiya S. Calibration curve for quantitative analysis of the monoclinic-tetragonal ZrO2 system by X-ray diffraction. J Am Ceram Soc. 1984;67:C-119-C-21.

[18] ISO 13356. 2015, implants for surgery- ceramic materials based on yttria-stabilized tetragonal zirconia (Y-TZP). Geneve, Switzerland: International Organization for Standarization; 2008.

[19] Albrektsson T, Wennerberg A. Oral implant surfaces: part 1 - Review focusing on topographic and chemical properties of different surfaces and in vivo responses to them. Int J Prosthodont. 2004; 17:536-543.

[20] Sato H, Yamada K, Pezzotti G, et al. Mechanical properties of dental zirconia ceramics changed with sandblasting and heat treatment. Dent Mater J. 2008;27 (3):408-414.

[21] Sato H, Ban S, Nawa M, et al. Effect of grinding, sandblasting and heat treatment on the phase transformation of zirconia surface. Key Eng Mater. 2007;330332:1263-1266.

[22] Tanaka K, Tamura J, Kawanabe K, et al. Phase stability after aging and its influence on pin-on-disk wear properties of $\mathrm{Ce}-\mathrm{TZP} / \mathrm{Al} 2 \mathrm{O} 3$ nanocomposite and conventional Y-TZP. J Biomed Mater Res A. 2003;67(1):200-207. .

[23] ISO 10993-5. 2009 biological evaluation of medical devices-part 5: tests for in vitro cytotoxicity. Geneva: International Organization for Standardization; 2009.

[24] Huang N, Yang P, Leng YX, et al. Hemocompatibility of titanium oxide films. Biomaterials. 2003;24 (13):2177-2187. .

[25] Williams DF, European Society for B. Definitions in biomaterials: proceedings of a consensus conference of the European Society for Biomaterials, Chester, England, March 3-5, 1986. Amsterdam; New York: Elsevier.

[26] Faia-Torres AB, Guimond-Lischer S, Rottmar $M$, et al. Differential regulation of osteogenic differentiation of stem cells on surface roughness gradients. Biomaterials. 2014;35(33):9023-9032. .

[27] Zhang Y, Chen SE, Shao J. van den Beucken JJJP. Combinatorial surface roughness effects on osteoclastogenesis and osteogenesis. ACS Appl Mater Interfaces. 2018;10(43):36652-36663.

[28] Lee EM, Smith K, Gall K, et al. Change in surface roughness by dynamic shape-memory acrylate networks enhances osteoblast differentiation. Biomaterials. 2016;110:34-44.

[29] Hempel U, Hefti T, Kalbacova M, et al. Response of osteoblast-like SAOS-2 cells to zirconia ceramics with different surface topographies. Clin Oral Implants Res. 2010;21(2):174-181.

[30] Kosmač T, Oblak $\check{C}$, Jevnikar $P$, et al. Strength and reliability of surface treated Y-TZP dental ceramics. J Biomed Mater Res. 2000;53(4):304-313.

[31] Wu -C-C, Wei C, Ho -C-C, et al. Enhanced hydrophilicity and biocompatibility of dental zirconia ceramics by oxygen plasma treatment. Materials. 2015;8(2):684-699.

[32] Gautam C, Joyner J, Gautam A, et al. Zirconia based dental ceramics: structure, mechanical properties, biocompatibility and applications. Dalton Trans. 2016;45 (48):19194-19215.

[33] Wang W, Zhao L, Wu K, et al. The role of integrin-linked kinase/ $\beta$-catenin pathway in the enhanced MG63 differentiation by micro/nano-textured topography. Biomaterials. 2013;34:631-640.

[34] Czekanska EM, Stoddart MJ, Richards RG, et al. In search of an osteoblast cell model for in vitro research. Eur Cell Mater. 2012;24:1-17. 